\title{
CRM Fit and Relationship Quality in Hotel Industry
}

\author{
Jounghae Bang ${ }^{1}$ and Min Sun Kim²* \\ 1 Associate Professor, College of Business Administration, Kookmin University, Seoul, \\ Korea,bangjh@kookmin.ac.kr \\ 2* Assistant Professor, School of Tourism and Distribution Management, Hyupsung \\ University, Korea, sunnyminkim@hanmail.net, Corresponding Author
}

\begin{abstract}
Organizations have realized the importance of CRM. Even though CRM is spelled out to Customer Relationship Management, it has been overlooked the fact that the focus of CRM should be on customers and the relationship with them. As well, since the Internet has been widely used as a very effective medium for interacting with people no matter where they are and when it is, it is a useful tool to interact with customers. Therefore this study examined CRM practice and the Internet usage based on relationship quality and relational benefits theories. This study attempts to examine the effect of the FIT between each stage of CRM process and Internet usage for each stage. CRM Fit and relationship quality variables have been identified from the aspect of customers who have membership of a certain hotel. The results showed that the Fit for the maintenance stage has a positive effect on Commitment, which leads to Loyalty. Customer Orientation was also found significant to influence Satisfaction and Commitment. Interestingly Termination stage has a positive effect on Commitment while it has a negative effect on Satisfaction.
\end{abstract}

Keywords: CRM; customer; relationship; internet; satisfaction; commitment; loyalty

\section{Introduction}

It is widely known that a well-implemented Customer Relationship Management (CRM) plan increases profit because the customer retention cost is 5 to 7 times less than customer acquisition costs (Kotler, 1997), and also because profit can be boosted by $25 \%$ to $85 \%$ by reducing customer defections by $5 \%$ (Reichheld and Sasser, 1990).

However, one of the challenges is the fact that the businesses do not know their customers. Davenport, Harris, and Kohli (2001) noted that even companies, which have a huge data warehouse, have few additional insights about their customers. A Gartner study indicated that up to 80 percent of enterprises did not understand how CRM creates value in their customer base (Kirkby, 2002). Furthermore, it is well recognized that relational value is important (Kandampully, 1998); yet, in reality, there are not many translating this idea into viable practice (Gamble, Stone, and Woodcock, 1999). Therefore, to gain better insights about CRM practice, we need to scrutinize CRM practice from customer focused, relationship oriented approach. Such a view of CRM will provide better theoretical background to enhance the understanding of as well as improve the practice of CRM.

Therefore, the focus of the study is on customers' perception on relationship quality rather than managerial issues of CRM. The issue of this study is in this question: how to establish and maintain good relationships with customers (1) by using the Internet (2) from the relationship quality perspectives. 


\section{Conceptual Framework}

Figure 1 below shows the research model. This model has (1) CRM Fit including CRM Process and Internet Usage for each stage of CRM, (2) relationship quality in terms of customers' perceived level of Satisfaction, Commitment, and Loyalty, and (3) Customer Orientation and Customer Knowledge Process. CRM is a core business strategy to deliver value to targeted customers to improve customer satisfaction and customer retention at a profit (Ang and Buttle, 2002). Since the basic goal of CRM is to improve customer satisfaction and retention, relationship quality which includes loyalty, satisfaction, and commitment is included as customers' aspects of CRM Performance in the model.

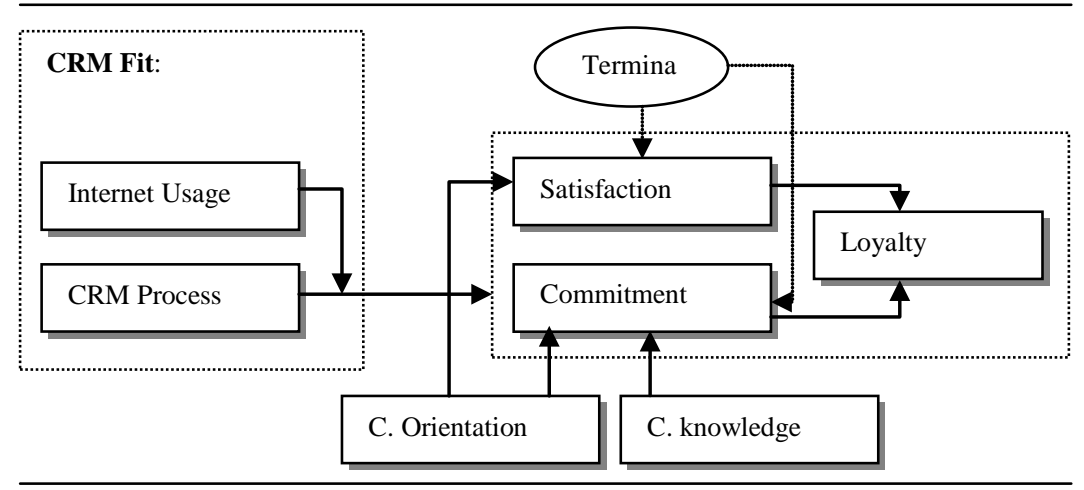

Figure 1. Research Model

\subsection{Relationship Quality - Satisfaction, Commitment, and Loyalty}

In CRM Performance, Satisfaction, Loyalty and Commitment are included. Satisfaction and Commitment are viewed as not only the result of interaction with the businesses over time (Anderson, Fornell and Lehmann, 1994; Crosby, Evans and Cowles, 1990) but also as core variables in relationship quality (Hennig-Thrau, Gwinner, and Gremler, 2002).

Oliver (1997) defined satisfaction as pleasurable fulfillment. Consumers find consumption pleasurable when consumption fulfills their needs, desires, and goals. While this perspective on satisfaction appears to be transaction-specific, recent research has focused more on satisfaction as relationship-specific (Shankar, Smith, and Rangaswamy, 2000). As another core variable of relationship quality, commitment has been recognized (Roberts, Varki, and Brodie, 2003; Hennig-Thrau, Gwinner, and Gremler, 2002). Commitment is defined as "an enduring desire to maintain a valued relationship" (Moorman, Zaltman, and Deshpande, 1992). Commitment is found to be an indicator of service relationships since relationships are built upon the foundation of mutual commitment (Parasuraman and Berry, 1991). In this study, Commitment is viewed from affective and cognitive aspects and measured as importance of the relationship and degree to which the person is committed to the relationship. The importance of loyal customers to the business has been well recognized because they help the business in many different ways. Loyal customers usually spend more, buy more frequently, are more likely to be involved in positive word-of-mouth, and are more tolerant of businesses' temporary failures (Dick and Basu, 1994). Even though loyalty continues to be defined in some circles as repeat purchasing frequency, more and more researchers are defining loyalty as a construct consisting of both behavioral and cognitive components (Dick and Basu, 1994; Oliver, 1999; Lim and Razzaque, 1997). In this study, Loyalty is measured as degree of perceived strength of relationship and recommendation behavior. 


\subsection{CRM Fit}

CRM Process was identified to have three stages - initiation (gain, regain the relationship with customers), maintenance of the relationship, and termination of the relationship (Reinartz, Krafft, and Hoyer, 2004). In the initiation stage, a business attempts to attract prospects with different offers. Likewise, a business attempts to up-sell and cross-sell their product or service during the maintenance stage while customers will have the customized individualized offers related to their previous purchase of service. CRM Process is viewed as a systematic process to manage customer relationship initiation and maintenance across all customer contact points in order to maximize the value of the relationship portfolio (Reinartz, Krafft, and Hoyer, 2004).

In order to explain the effect of CRM Fit, TTF model from MIS is adopted and adapted. Task-Technology Fit in the TTF model is defined as the degree to which a technology assists a person in performing his/her tasks (Goodhue and Thompson, 1995). Here CRM Fit for each stage of CRM process is the interaction effects of CRM efforts and the Internet usage for the initiation and maintenance stage of CRM process. Since the Internet is a new good medium to interact with customers, it is expected that well-designed internet usage for CRM stages will help interact with customers more effectively and therefore lead companies to the better CRM performance, relationship quality.

The termination stage, however, should be examined separately from this CRM Process from the customers' perspective. Termination represents organizational control for enhancing profit rather than a business operation for mutually beneficial relationship. Therefore, termination stage is included as a separate variable in the model for additional understanding.

\section{Research Hypotheses}

\subsection{CRM Fit}

Since well-designed CRM Process will improve the ability to recognize customers' value (Reinartz, Krafft, and Hoyer, 2004), it is expected that well-designed Regain Stage Process will lead to customers' Satisfaction and Commitment by offering individualized attractive deals to customers. Similarly, well-designed maintenance stage is also expected to influence Satisfaction and Commitment by providing individualized special services. Customizing offers to individual customer preferences has been seen as a key component of CRM (Freeland, 2003; Lemon, White, and Winer, 2002; Winer, 2001).

The Gain stage is geared toward potential customers or prospects. Most potential customers become customers for the firm through general attraction instead of individualized special offers. Therefore the effect of gaining stage is expected to be limited. Therefore we expect:

H1: CRM fit (gain, regain, and maintain stages) will have a positive effect on (1) Commitment and (2) Satisfaction.

In addition, Termination stage is expected to have a negative effect on commitment and satisfaction. Even though customers know that they are not profitable customers for the business, it is plausible that customers would want to be treated as a king if they are buyers no matter how often they buy. The Termination stage is about reduction of services or increasing service fees to terminate the relationship. Therefore,

H2: Termination stage process will have a negative effect on (1) Commitment and (2) Satisfaction. 


\subsection{Customer Orientation \& Customer Knowledge Process}

Customer Orientation as an atmosphere or organizational culture that customers perceive and Customer Knowledge Process as companies' efforts to increase their knowledge on customers are included in this model. Customer Orientation is viewed as customers' perception of the firm's atmosphere and culture to understand customers' needs while Customer Knowledge Process is viewed as customers' perception of firm's knowledge about customers.

Customer Orientation, because culturally salespeople tend to practice and show the marketing concept by helping their customers, will satisfy the customers' needs (Saxe and Weitz, 1982; Siguaw, Brown, and Widing, 1994). As such, if customers perceive that employees try to understand and help the customers, it is expected to lead to customer Satisfaction and Commitment. Also, it is also possible that customers would be more committed if customers perceive that the firm tries to learn about them to improve the service. It is postulated that Customer Knowledge Process would have positive effect on Commitment. However, due to the privacy issues, the effect is not expected to be strong.

H3: Customer Orientation will have a positive effect on (1) Commitment and (2) Satisfaction.

H4: Customer Knowledge Process will have a positive effect on Commitment.

\subsection{Relationships between Loyalty, Commitment and Satisfaction}

Most prior research has reported that satisfaction has a positive effect on customer loyalty (Bloemer and Ruyter, 1998; Rust and Zahorik, 1993; Szymanski and Henard, 2001). The relationships between satisfaction and store loyalty (Bloemer and Ruyter, 1998), and customer satisfaction and store loyalty via repurchase intentions (Baker-Prewitt and Sivadas, 2000) are found to be significant. Gronholdt, Martensen and Kristersen (2000); in particular, there are significant customer satisfaction-customer loyalty relationships at the organizational level.

Also, a high level of satisfaction leads the customers to create commitment-inducing emotional bonds via repeated positive reinforcement (Hennig-Thurau, Gwinner, and Gremler, 2002). Since satisfaction is pleasurable fulfillment (Oliver, 1997), it is related to the fulfillment of social needs and this repeated fulfillment is likely to increase emotional bonds (Hennig-Thurau and Klee, 1997). Commitment is also found to influence loyalty positively (Pritchard, Havitz, and Howard, 1999).

One study, however, found different effects of satisfaction and commitment based on customers' relational level (Garbarino and Johnson, 1999). In this study, infrequent individual theater ticket buyers are viewed as low relational customers while consistent subscribers are seen as high relational customers. Overall satisfaction was found to lead to commitment for low relational customers. For high relational customers, commitment - rather than satisfaction - is the mediator between attitudes and future intentions to buy. As such, it is expected that for people who already have membership accounts such as frequent flyer (mileage) programs or frequent user reward programs, commitment would lead to satisfaction level while satisfaction would influence commitment for those who do not have membership status. Therefore, it is expected:

H5: (1) Satisfaction and (2) Commitment will have positive effects on Loyalty 


\section{Additional Study: Relational Benefit Mediating Model}

Additionally, the relational-benefit mediating model is introduced. The two popular approaches in relationship marketing are relational benefit approach and relationship quality approach (Hennig-Thurau, Gwinner, and Gremler, 2002). Relational benefits are referred to "benefits that customers likely receive as a result of having cultivated a long-term relationship with a service provider including confidence benefits, social benefits, and special treatment benefits" (Gwinner, Gremler, and Bitner, 1998). Gamble, Stone, and Woodcock (1999) noted in their definition of CRM that building relationships with customers is based on mutual benefit. The relational benefits are those perceived by customers. Therefore, it is expected that via CRM practice, a firm will create relational benefits for customers to build and strengthen the relationship. Therefore, this study additionally examines the mediating effect of Relational Benefits to see the relationship between CRM Process and Performance in customers' perspective.

\section{Methodology}

\subsection{Data Collection}

Data were collected using web-enabled surveys. Subjects for this study are hotel customers - business travelers and personal travelers. People who had stayed at a hotel within a year were invited to participate in the survey. The questions were not about a specific hotel, but about a hotel chain which respondent had used most often within a year. This is because it is less likely that people on the move would stay at the same exact hotel all the times, even when they are very satisfied and loyal. Rather, it would be much more likely that they would find a hotel under the same hotel chain.

The online survey was viewed by 447 people. Among them, 361 started the survey. Only 239, however, completed the survey. Completion/view rate was 53.47\%, while completion/start rate was $66.2 \%$. To clean the data, descriptive and frequency analysis were conducted and it was found that 220 responses were usable. However, only 102 respondents who have membership with a hotel were used because this study is about CRM process of which a maintenance stage is essential.

\subsection{Measures}

The measures are 7-point Likert scale items (strongly agree - strongly disagree) with not applicable option. Measure items for CRM process are adapted from Reinartz et al. (2004)'s study, and Internet Usage for each stage were developed accordingly. Customer orientation items are adapted from the studies of Narver and Slater (1990), Lytle, Hom and Mokwa (1998), and Homburg, Hoyer, and Fassnacht (2002) while measurement items for customer knowledge process were adapted and adjusted from the study of Li and Calantone (1998).

CRM process includes gain stage, regain stage, maintain stage, and terminate stage. For gain, regain, and maintain stages, the internet usage per stage items were included, which made total 16 items for 7 variables such as gain, internet usage for gain(below I-gain), regain, I-regain, maintain, I-maintain, and terminate. the reliabilities alphas for all the items were over $.8(.8168, .9449, .8580, .8180, .8332$, respectively except for gain and I-gain stage because they have only one item). The reliability coefficients were .8753 for Customer Knowledge Process and .9251 for Customer Orientation. The measures for Loyalty, Satisfaction, and Commitment were adopted and adapted from Hennig-Thurau, Gwinner, and Gremler (2002), Gwinner, Gremler and Bitner (1998), and Morgan and Hunt (1994). Loyalty 
measures include cognitive aspects and behavioral aspects such as word of mouth. Reliabilities for satisfaction, commitment and loyalty were .9172, .9461, and .7339 respectively.

For additional study, the items for relational benefit on additional sub-study as part of the customer study were adopted from Hennig-Thurau, Gwinner, and Gremler (2002). Relational benefits consist of social benefit, special treatment benefit, and confidence benefit. The reliabilities were .9632 for Social Benefit, .9201 for Special Treatment Benefit, and .9471 for Confidence Benefit.

\subsection{Analysis}

Using LISREL 8.3, data analysis with Structural Equation Modeling (SEM) was employed to test the proposed models. SEM is often used as a confirmatory analysis tool, but it is also used for theory development (Raykov and Marcoulides, 2000; Hair et. al., 1998). While various paths linking the variables have been suggested through the literature review, the field studied in this dissertation is largely unexplored. Therefore, all the proposed models including relational benefit-mediating models were investigated. As well, due to this small sample size, the analyses were conducted in two separate ways - confirmatory factor analysis for measurement model and path analyses for structural model.

\subsection{CFA Results}

First, construct reliability was examined using composite reliability and average variance extracted (AVE). Composite reliabilities for all variables were .70, which exceeds .60, the cutoff recommended by Bagozzi and Yi (1988). Also, AVEs for all variables were over .50 (Fornell and Larcker, 1981). These two results indicate good construct reliability.

Second, convergent validity and discriminant validity were examined. For overall fit, GFI indicates a moderately good fit (.84), but CFI and Tucker-Lewis Index (TLI) are .94 and .92, respectively. Since GFI is considerably influenced by variations in sample size and nonnormality of the measures, it is recommended that CFI and TLI be examined as alternative measures of fit as they are more robust (Burton et al., 1998). CFI and TLI in this instance are higher than 0.9, the advocated fit level (Roberts, Varki, and Brodie, 2003), and indicate a good fit. $\chi^{2}$ was 638.69 with 284 degree of freedom. Loadings were all significant at $p<.05$, and their Squared Multiple Correlations (SMCs) exceed 0.50, the cutoff recommended by Bagozzi and Yi (1988).

\subsection{Path Analysis Result}

The model with CRM Fit indicates good fit with chi-square (21 degree of freedom) $=$ $32.08, p=0.058$, RMSEA $=0.057 p=.39$, GFI $=.94$, and CFI $=.97$ even though RMSEA is a little bit higher than .05 .

In the path analysis, the Fit in the maintenance stage was significantly associated with Commitment (coefficient $=0.05, \mathrm{t}=2.59$ ), but not with Satisfaction. Termination stage was found significantly related to both Satisfaction (coefficient $=-.16, \mathrm{t}=2.69$ ) and Commitment (coefficient $=0.23$, $\mathrm{t}=2.24$ ).

It was found that there are positive paths from Commitment to Loyalty (coefficient $=0.66$, $\mathrm{t}=11.85$ ), from Satisfaction to Loyalty (coefficient $=0.29$, $\mathrm{t}=3.29$ ), and from Customer Orientation to Satisfaction (coefficient $=0.41, \mathrm{t}=5.00$ ) and to Commitment(coefficient $=0.46$, $\mathrm{t}=3.43$ ). The effect of Customer Knowledge Process was not found significant to either Commitment or Satisfaction. 
Commitment and Satisfaction are both well-known core variables for relationship quality, and these results again added one more example in support of such theory. Unexpectedly, there was no significant relationship between Commitment and Satisfaction. Customers' perception of Customer Orientation of a hotel chain was found to have significant positive association with Satisfaction. Commitment was found to mediate CRM Process and CRM Performance for members. With members' data, CRM Fit in Maintenance Stage has a positive effect on Commitment but not on Satisfaction.

\subsection{Additional Studies: Analysis for the Mediating Effect of Relational Benefits}

Relational Benefits were included as mediating variables in the research model. The overall fit of the model was not good and worse than the model without relational benefits. Therefore relational benefits do not seem to play an important mediating role in this model.

\section{Discussion, Conclusions and Implications}

\subsection{Discussion and Conclusions}

CRM Process was viewed as overall concept of gain, regain, and maintain stages. As expected, maintain stage was found to have significant impact, but not other stages. Again, most of CRM practice is likely concentrated on the "maintain stage"; and larger and more varied samples may be needed to assess other stages. The terminate stage was found to have a negative effect on satisfaction level. This indicates that customers would want to be treated as valuable customers even though firms may regard them as not valuable customers. The idea of termination decreases the satisfaction level. Subtle and sophisticated tactics may be needed at the termination stage, tactics that are not obvious to customers, to enhance CRM Performance. However the same idea of termination increases commitment level to hotel members.

Commitment and Satisfaction had been identified as core variables for relationship quality, and it was found that there are strong positive relationships with Loyalty. Therefore CRM Process should be designed to enhance Commitment and Satisfaction levels. Based on the results of analyses, the Maintain Stage was the almost the only stage that showed significant relationships with relationship quality. This implies that there could be opportunities to enhance CRM Performance by utilizing CRM stages beyond just the Maintain Stage. The CRM Fit in Maintain stage has a positive relationship with Commitment, not with Satisfaction for members.

Customer Orientation was found to have a significant relationship with Satisfaction and therefore to be important for customers. Furthermore, Customer Orientation was found to have a positive relationship with Commitment for members. This means that if hotel members perceive a hotel as seriously attempting to understand customers, and all the employees are encouraged to help customers by understanding customer requirements, then the members are most likely to increase their commitment as well as satisfaction level.

\subsection{Limitations}

The data set was not big enough to use full structural equation modeling. Therefore, in this study, only path analyses were conducted. Regarding the Relationship Marketing approach, Trust - one of the core relationship quality measures - was not included in the model. The Confidence Benefit contained the trust concept, but the model fit was not good. Therefore Trust may not be the critical variable in this particular study. In full and comprehensive investigations of relationship quality and relational benefits, however, Trust would have to be 
treated explicitly in the models. Furthermore, clear distinction in the definitions of Loyalty and Commitment are needed. Loyalty has been defined in many studies from multiple aspects such as cognitive, affective, and behavioral, and Commitment may not be clearly distinguished from affective or cognitive aspect of Loyalty. In this study, exploratory Factor Analysis and CFA indicated good fit in measurement model, but further refined measurement items for Loyalty and Commitment would improve the model fit.

\subsection{Contributions, Implications and Future Research}

Despite the limitations, the research presented has theoretical and practical implications the study theoretically sheds light on the importance of customer-centric management as well as information technology in CRM practice. The findings showed that CRM Process was significantly associated with CRM Performance. The major benefits of this study to the managers would be closer matching of the Internet usage and CRM Process, leading to increasing levels of customer satisfaction and customer retention. The concept of CRM Fit would help managers understand the importance of well designed Internet usage for CRM process. The distinction between cultural norm and the organizational process for customer knowledge were examined empirically in the context of CRM. Customer Orientation was an important factor for satisfaction and commitment for the hotel members. A practical implication is that members are likely to respond well to a perceived customer friendly corporate culture

Based on the research presented here, several issues for future research have become evident. Future research is needed not just to overcome some of the limitations but also to extend the work presented here. This study only examined members of hotels. It will be interesting to see how non-members perceive the CRM efforts. Also the modification index of path analyses results suggested the paths from relationship quality to relational benefit as a way to improve the model fit. The paths were not investigated because literature review had pointed towards other paths from relational benefit to relationship quality. It would be interesting, however, to examine possible differences in the paths between relational benefits and relationship quality for non-member and member categories of customers. Additionally, the Internet and mobile technology have emerged as a major new medium for customers to interact with firms and as a new tool for information search, information delivery, and shopping. This study did not have the opportunity to thoroughly investigate the all other roles of Internet and mobile technology, which becomes more individual, in CRM settings. Studies of the impact of Internet on CRM would be insightful for managers in that they can employ this unique medium with mobile technology more effectively for enhancing the prospecting and customer retention.

\section{References}

[1] E. W. Anderson, C. Fornell and D. R. Lehmann, "Customer Satisfaction, Market Share, and Profitability: Findings from Sweden", Journal of Marketing, http://www.jstor.org/stable/1252310 10.2307/1252310, ISSN 0022-2429, vol. 58, (1994), pp. 53-66.

[2] L. Ang and F. A. Buttle, "ROI on CRM: A Customer-journey Approach", www.CRM2DAY.com., http://impgroup.org/uploads/papers/4225.pdf, (2002).

[3] R. P. Bagozzi, and Y. Yi., "On the Evaluation of Structural Equation Models", Journal of the Academy of Marketing Science, Spring, DOI: 10.1007/BF02723327, vol. 16, (1988), pp. 74-94.

[4] J. Baker-Prewitt and E. Sivadas, "An Examination of the Relationship between Service Quality, Customer Satisfaction, and Store Loyalty", International Journal of Retail \& Distribution Management, DOI: 10.1108/09590550010315223, vol. 128, no. 2 (2000), pp. 73-82. 
[5] S. Burton, D. R. Lichtenstein, R. G. Netemeyer and J. A. Garretson, "A Scale of Measuring Attitude toward Private Label Products and An Examination of Its Psychological and Behavioral Correlates", Journal of the Academy of marketing Science, DOI: 10.1177/0092070398264003, vol. 26, no. 4, (1998), pp. 293-306.

[6] E. J. Choi and S.-H. Kim, "The Study of the Impact of Perceived Quality and Value of Social Enterprises on Customer Satisfaction and Re-Purchase Intention", IJSH, http://www.sersc.org/journals/IJSH/vol7_no1_ 2013/22.pdf, ISSN 1975-4094, vol. 7, no. 1, (2013), pp. 239-252.

[7] L. A. Crosby, K. R. Evans and D. Cowles, "Relationship Quality in Services Selling: An Interpersonal Influence Perspective", Journal of Marketing, http://www.jstor.org/stable/1251817 10.2307/1251817, vol. 54, (1990), pp. 68-81.

[8] T. H. Davenport, J. G. Harris and A. K. Kohli. "How Do They Know Their Customers So Well?", Sloan Management Review, http://dialnet.unirioja.es/servlet/articulo?codigo=2474000, ISSN 1532-9194, (2001), pp. 63-73.

[9] A. Dick and K. Basu, "Customer Loyalty: An Integrated Conceptual Framework", Journal of Academy of Marketing Science, DOI: 10.1177/0092070394222001, vol. 22, (1994), pp. 99-113.

[10] C. Fornell and D. F. Larcker, "Evaluating Structural Equation Models with Unobservalbe Variables and Measurement Error", Journal of Marketing Research, http://www.jstor.org/stable/3151312 10.2307/3151312, ISSN 0022-2437, vol. 19, no. 4, (1981), pp. 440-452.

[11] J. G. Freeland, "The Ultimate CRM Handbook", New York: McGraw-Hill, No. Katalog 6.368, Klasifikasi 658.812, (2003).

[12] P. R. Gamble, M. Stone and N. Woodcock, "Up Close and Personal?", London: Kogan Page Ltd., ISBN 07494-4691-9, (1999).

[13] E. Garbarino and M. S. Johnson, "The Different Roles of Satisfaction", Trust, and Commitment in Customer Relationships. Journal of Marketing, http://www.jstor.org/stable/1251946 10.2307/1251946, ISSN 00222429, , vol. 63, (1999), pp. 70-87.

[14] D. L. Goodhue and R. L. Thompson, "Task-Technology Fit and Individual Performance", MIS Quarterly, http://www.jstor.org/stable/249689 10.2307/249689, ISSN 0276-7783, (1995), pp. 213-236.

[15] L. Gronholdt, A. Martensen and K. Kristersen, "The Relationship Between Customer Satisfaction and Loyalty: Cross-Industry Differences", Total Quality Management, DOI: 10.1080/09544120050007823, vol. 11, (2000), pp. 509-514.

[16] K. Gwinner, D. D. Gremler and M. J. Bitner, "Relational Benefits in Services Industries: The Customer's Perspective", Journal of the Academy of marketing Science, DOI: 10.1177/0092070398262002, vol. 26, no. 2, (1998), pp. 101-114.

[17] J. F. Hair, R. E. Anderson, R. L. Tatham and W. C. Black, "Multivariate Data Analysis", $5^{\text {th }}$ Edition, Ed. Whitney Blake, Prentice-Hall, NJ: Upper Saddle River, http://www.lavoisier.fr/livre/notice.asp?ouvrage=1115189, (1998).

[18] T. Hennig-Thurau, K. P. Gwinner and D. D. Gremler, "Understanding Relationship Marketing Outcomes: An Integration of Relational Benefits and Relationship Quality", Journal of Service Research, DOI: 10.1177/1094670502004003006, vol. 4, no. 3, (2002), pp. 230-247.

[19] T. Hennig-Thurau and A. Klee, "The Impact of Customer Satisfaction and Relationship Quality on Customer Retention-A Critical Reassessment and Model Development", Psychology \& Marketing, DOI:10.1002/(SICI)1520-6793(199712)14:8<737::AID-MAR2>3.0.CO;2-F.

[20] C. Homburg, W. D. Hoyer and M. Fassnacht. "Service Orientation of a Retailer's Business Strategy: Dimensions, Antecedents, and Performance Outcomes", Journal of Marketing, http://www.jstor.org/stable/3203360 10.2307/3203360, ISSN 0022-2429, vol. 66, (2002), pp. 86-101.

[21] M. Javed, B. Ahmad, M. Ali Abid, M. Ahmad Jan Sheikh Muhammad Saqib and M. Ali Shah, "Effort Reduction in RUP using CRM for Project Development: Mapping the Best Practices of CRM into RUP", IJAST, ISSN 2005-4238, vol. 47, (2012), pp. 43-50.

[22] M. Javed, B. Ahmad, M. Ahmad Jan, M. Ali Abid and M. Ali Shah, "RUP Certification via CRM Certification Process: Development of Software with Zero Defect Rate", IJAST, http://www.sersc.org/journals/IJAST/vol48/1.pdf, , ISSN 2005-4238, , vol. 48, (2012), pp. 1-10.

[23] J. Kandampully, "Service Quality to Service Loyalty: A Relationship Which Goes Beyond Customer services", Total Quality Management, DOI: 10.1080/0954412988370, vol. 9, no. 6, (1998), pp. 431-443.

[24] J. Kirkby, "What Is a Customer Relationship Management Strategy?", Gartner Group Research Note, TU-186121, (2002).

[25] P. Kotler, "Marketing Management: Analysis, Planning and Control", 9 ${ }^{\text {th }}$ ed., Prentice-Hall, London, (1997).

[26] K. N. Lemon, "Tiffany Barnett White, and Russell S. Winer", Dynamic Customer Relationship Management: Incorporating Future Considerations into the Service Retention Decision", Journal of Marketing, http://www.jstor.org/stable/3203366 10.2307/3203366, ISSN 0022-2429, vol. 66, (2002), pp. 1-14. 
[27] T. Li and R. J. Calantone, "The Impact of Market Knowledge Competence on New Product Advantage: Conceptualization and Empirical Examination", Journal of Marketing, http://www.jstor.org/stable/1252284 10.2307/1252284, ISSN 0022-2429, vol. 62, (1998), pp. 13-29.

[28] K. S. Lim and M. A. Razzaque, "Brand Loyalty and Situational Effects: An Interactionist Perspective", Journal of International Consumer Marketing, DOI: 10.1300/J046v09n04_06, vol. 9, no. 4, (1997), pp. 95115.

[29] R. S. Lytle, P. W. Hom and M. P. Mokwa, "SERV*OR: A Managerial Measure of Organizational ServiceOrientation", Journal of Retailing, http://dx.doi.org/10.1016/S0022-4359(99)80104-3, vol. 74, no. 4, (1998), pp. 455-489.

[30] C. Moorman, G. Zaltman and R. Deshpandé, "Relationships between Providers and Users of Market Research: The Dynamics of Trust within and between Organizations", Journal of Marketing Research, https://faculty.fuqua.duke.edu/ moorman/Publications/JMR1992.pdf, http://www.jstor.org/stable/3172742 10.2307/3172742, vol. 26, (1992), pp. 314-328.

[31] R. M. Morgan and S. D. Hunt, "The Commitment-Trust Theory of Relationship Marketing", Journal of Marketing, http://www.jstor.org/stable/1252308, 10.2307/1252308 ISSN 0022-2429, vol. 58, (1994), pp. 2038.

[32] J. C. Narver and S. F. Slater, "The Effect of a Market Orientation on Business Profitability", Journal of Marketing, http://www.jstor.org/stable/1251757 10.2307/1251757 ISSN 0022-2429, vol. 54, (1990), pp. 2035.

[33] R. Oliver, "Satisfaction: A Behavioral Perspective on the Consumer", New York: Irwin/McGraw-Hill, http://books.google.co.kr/books?hl=ko\&lr=\&id=IJ5846z99tIC\&oi=fnd\&pg=PR3\&dq=+Satisfaction:+A+Be havioral+Perspective+on+the+Consumer\&ots=hwdLADcxw9\&sig=pp1tWXmhN2tyFwr55nVamWpKcAg\#, ISBN 0070480257, (1997).

[34] R. Oliver, "Whence Consumer Loyalty?", Journal of Marketing, http://www.jstor.org/stable/1252099 10.2307/1252099, vol. 63, (1999), pp. 33-44.

[35] A. Parasuraman, , L. L. Berry and Valerie A. Zeithaml, "Understanding Customer Expectations of Service", Sloan Management Review, http://ssrc.nccu.edu.tw/upload/paper_reading/2007/Katrina_2007_10_01.pdf, (1991), pp. 39-47.

[36] M. P. Pritchard, M. E. Havitz and D. R. Howard, "Analyzing the Commitment-Loyalty Link in Service Contexts", Journal of the Academy of marketing Science, DOI: 10.1177/0092070399273004, vol. 27, (1999), pp. 333-348.

[37] T. Raykov and G. A. Marcoulines, "A First Course In Structural Equation Modeling", Lawrence Erlbaum Associates, NJ: Mahwah, (2000).

[38] F. F. Reichheld and W. E. Sasser, "Zero Defections Quality comes to Services", Harvard Business Review, http://www.ventes-marketing.com/References/Exploitation\%20de\%20la\%20loyaute/Articles\%20generaux/ Zero\%20Defection.pdf, (1990), pp. 301-307.

[39] W. Reinartz, M. Kraff and W. D. Hoyer, "The Customer Relationship Management Process: Its Measurement and Impact on Performance", Journal of Marketing Research, http://www.jstor.org/stable/30162340 10.2307/30162340, ISSN 0022-2437, , vol. 41, no. 3, (2004), pp. 293.

[40] K. Roberts, S. Varki, and R. Brodie, "Measuring the Quality of Relationships in Consumer Services: An Empirical Study", European Journal of Marketing, DOI: 10.1108/03090560310454037, vol. 37, no. 1-2, (2003), pp. 169-196.

[41] R. T. Rust and A. Zahorik, "Customer Satisfaction, Customer Retention, and Market Share", Journal of Retailing, http://dx.doi.org/10.1016/0022-4359(93)90003-2, vol. 69, no. 2, (1993), pp. 193-216.

[42] R. Saxe and B. A. Weitz, "The SOCO Scale: A Measure of the Customer Orientation of Salespeople", Journal of Marketing Research, http://www.jstor.org/stable/3151568 10.2307/3151568, vol. 19, (1982), pp. 343-351.

[43] V. Shankar, A. K. Smith and A. Rangaswamy, "Customer Satisfaction an Loyalty in Online and Offline Environments", Retrieved February 16, 2001, from http://www.ebrc.psu.edu/papers/abstract/02-2000.html, (2000).

[44] J. A. Siguaw, G. Brown and R. E. Widing, "The Influence of the Market Orientation of the Firm on Sales Force Behavior and Attitudes", Journal of Marketing Research, http://www.jstor.org/stable/3151950 10.2307/3151950, vol. 31, (1994), pp. 106-116.

[45] D. M. Szymanski and D. H. Henard, "Customer Satisfaction: A Meta-Analysis of the Empirical Evidence", Journal of the Academy of Marketing Science, DOI: 10.1177/009207030102900102, vol. 29, (2001), pp. 1635.

[46] R. S. Winer, "A Framework for Customer Relationship Management. California Management Review", http://groups.haas.berkeley.edu/fcsuit/pdf-papers/crm\%20paper.pdf, vol. 43, no. 4, (2001), pp. 89-105. 


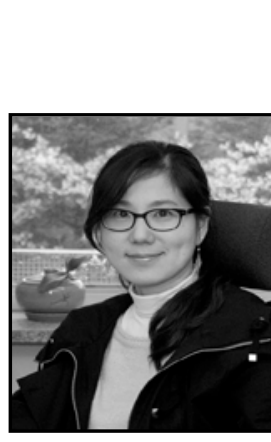

\section{Authors}

Jounghae Bang, she has her Ph.D in Marketing from College of Business Administration, University of Rhode Island, USA. Currently she is a faculty member in College of Business Administration, Kookmin University, Seoul, Korea. Her research interests include Customer Relationship Management, service design, and luxury marketing. She can be reached at bangjh@kookmin.ac.kr.

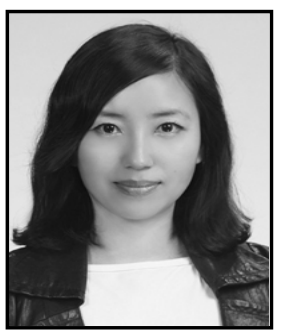

Min Sun Kim, she got her Ph.D. in Management Information System from Ewha Womens University, Korea. She is currently is a faculty member in School of Tourism and Distribution Management, College of Business Administration, Hyupsung University, Korea. Her current research interests include Smart work, ubiquitous, ebusiness, distribution management including CRM, and Hotel and Tourism management. She can be reached at sunnyminkim@hanmail.net. 
International Journal of Smart Home Vol.7, No.6 (2013) 